\title{
Pulse Analysis Spectroradiometer System for Measuring the Spectral Distribution of Flash Solar Simulators
}

\section{Preprint}

Afshin M. Andreas and Daryl R. Myers

To be presented at the SPIE Optics and Photonics 2008 Conference: Optical Modeling and Measurements for Solar Energy Systems II San Diego, California

August 10-14, 2008
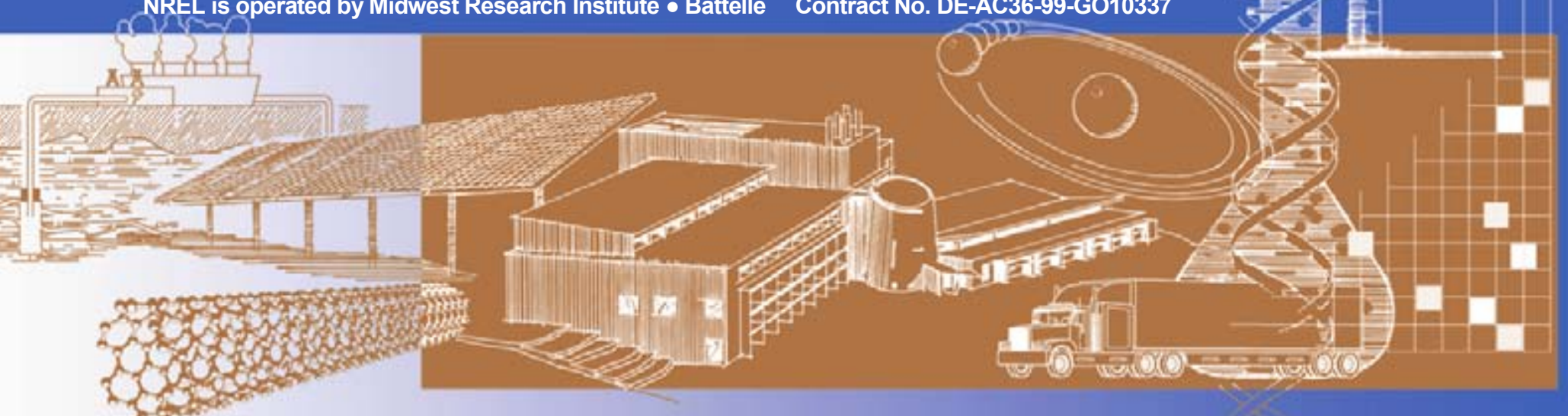


\section{NOTICE}

The submitted manuscript has been offered by an employee of the Midwest Research Institute (MRI), a contractor of the US Government under Contract No. DE-AC36-99G010337. Accordingly, the US Government and MRI retain a nonexclusive royalty-free license to publish or reproduce the published form of this contribution, or allow others to do so, for US Government purposes.

This report was prepared as an account of work sponsored by an agency of the United States government. Neither the United States government nor any agency thereof, nor any of their employees, makes any warranty, express or implied, or assumes any legal liability or responsibility for the accuracy, completeness, or usefulness of any information, apparatus, product, or process disclosed, or represents that its use would not infringe privately owned rights. Reference herein to any specific commercial product, process, or service by trade name, trademark, manufacturer, or otherwise does not necessarily constitute or imply its endorsement, recommendation, or favoring by the United States government or any agency thereof. The views and opinions of authors expressed herein do not necessarily state or reflect those of the United States government or any agency thereof.

Available electronically at http://www.osti.gov/bridge

Available for a processing fee to U.S. Department of Energy and its contractors, in paper, from:

U.S. Department of Energy

Office of Scientific and Technical Information

P.O. Box 62

Oak Ridge, TN 37831-0062

phone: 865.576 .8401

fax: 865.576 .5728

email: mailto:reports@adonis.osti.gov

Available for sale to the public, in paper, from:

U.S. Department of Commerce

National Technical Information Service

5285 Port Royal Road

Springfield, VA 22161

phone: 800.553 .6847

fax: 703.605.6900

email: orders@ntis.fedworld.gov

online ordering: http://www.ntis.gov/ordering.htm 


\title{
Pulse analysis spectroradiometer system for measuring the spectral distribution of flash solar simulators
}

\author{
Afshín M. Andreas*a , Daryl R. Myers ${ }^{\mathrm{a}}$ \\ ${ }^{a}$ National Renewable Energy Laboratory, 1617 Cole Blvd, Golden, CO, USA 80401
}

\begin{abstract}
Flashing artificial light sources are used extensively in photovoltaic module performance testing and plant production lines. There are several means of attempting to measure the spectral distribution of a flash of light; however, many of these approaches generally capture the entire pulse energy. We report here on the design and performance of a system to capture the waveform of flash at individual wavelengths of light. Any period within the flash duration can be selected, over which to integrate the flux intensity at each wavelength. The resulting spectral distribution is compared with the reference spectrum, resulting in a solar simulator classification.
\end{abstract}

Keywords: spectral distribution, solar simulator classification, flash solar simulator, pulse measurement system, waveform capture, spectroradiometer, monochromator, artificial light

\section{INTRODUCTION}

Artificial sources of light, filtered to match an Air Mass 1.5 reference terrestrial solar spectral distribution, are used extensively in photovoltaic (PV) module performance testing. These machines are also used in PV plant production lines to test each individual module and generate a label with the module electrical performance. Flashing units are used to avoid heating the module and maintain a fixed set of standard reporting conditions. Flashes may be of durations from 0.25 milliseconds (ms) to $500 \mathrm{~ms}$, depending on the design of the simulator. There are several means of attempting to measure the spectral distribution of a flash of light, including diode array spectrometers and filter radiometers. However, these approaches generally capture the entire pulse energy, despite the fact that measurement of the electrical performance parameters can be triggered to occur only over a very narrow portion of the pulse, typically at the pulse peak. At the National Renewable Energy Laboratory (NREL), we have developed the Pulse Analysis Spectroradiometer System (PASS) which is capable of measuring the absolute spectral content of pulsed light sources (or continuous light sources) with traceability to the National Institute of Science and Technology (NIST). For pulse light sources, the NREL developed software allows any period within the flash duration to be selected over which to integrate the flux intensity at each wavelength. The resulting spectral distribution is compared with the reference spectrum, resulting in a classification of the quality of the flash solar simulator spectral distribution.

This is especially important for technologies such as photovoltaics, where the appropriate design of PV devices (and knowing their efficiencies) depend on knowing how the devices respond to wavelength ranges in the solar spectrum (or, in this case, to a simulated solar spectrum). These measurements require advanced techniques compared to the measurement of continuous light sources; flashes are on the order of milliseconds long, so the instrument must be capable of either capturing an entire spectrum or recording the spectrum one wavelength at a time within the period of one pulse. Most commercially available spectroradiometers are incapable of making these measurements.

The data from the PASS can be used for many applications, including: American Society for Testing and Materials (ASTM) classification of the simulator, spectral mismatch corrections, effect of lamp and filter aging, effect of different optical environments on the spectra at the test plane, spectral changes within the pulse period, and the effect of lamp input current or voltage.

*afshin_andreas@nrel.gov; phone (303) 384-6383; fax (303) 384-6391; www.nrel.gov/solar_radiation 


\section{HOW SPECTRAL DATA IS COLLECTED}

The PASS spectral data is collected like any conventional grating-based monochromator system except that the data is acquired with a very high speed data acquisition system that is synchronized to the pulses generated by the solar simulator.

In a conventional grating-based monochromator like the PASS, light enters an integrating sphere that diffuses the light and makes it uniform; the integration sphere has a field of view of nearly 180 degrees. The light then enters the monochromator system. Inside the monochromator, the light hits a diffraction grating which disperses the light into its individual wavelength components. Depending on the position of the grating (which is controlled through software), a certain wavelength of light will be directed at a detector, such as silicon, which will then produce a current proportional to that light. This current is then measured at each wavelength by a data acquisition system and is converted to engineering units using a calibration file for spectroradiometer. Typically a grating-based monochromator includes an order sorting filter to reject higher order magnitudes of light dispersed by the grating. These filters are usually long pass filters; however, NREL uses band pass filters in the UV to help reduce stray light. Depending on the wavelength range of the monochromator system, the instrument may include several gratings mounted on a turret because a single grating is not capable of large wavelength ranges, such as $300-1800 \mathrm{~nm}$. When a particular grating reaches its maximum effective wavelength limit, the software will switch to the next grating. The same is true for detectors; the system may start with silicon and then switch another detector, such as germanium or InGaAs in the infrared. The spectral bandwidth of the monochromator is determined by the slit width and the grating dispersion. The slits are placed at the entrance of the monochromator (after the integration sphere) and the exit (just before the detector). NREL typically configures our instruments to have a spectral bandwidth of 1 to $5 \mathrm{~nm}$.

\section{PASS DETAILS}

The two major components of the PASS are a monochromator system and a data acquisition system. The monochromator system is composed of a grating-based monochromator (with one to three gratings), integration sphere, order sorting filters, one or two detectors (behind the monochromator), and a broadband silicon detector which is used as a trigger and a stability monitor. The data acquisition system is composed of high bandwidth amplifiers, high speed analog-to-digital converter (digitizer), and NREL developed software running on a laptop computer.

The software can be configured to scan over a certain wavelength range, such as $280-1720 \mathrm{~nm}$ at $5 \mathrm{~nm}$ intervals (for a dual detector system). When the scan starts, the monochromator is positioned at $280 \mathrm{~nm}$ and waits for a trigger signal from the broadband silicon detector. When light source flashes, the trigger is received and it will then acquire data for a specified time, which is long enough to capture a single pulse from the simulator. The software will then average the data over the specified region of the pulse (such as the peak or the flat top region). The software then applies a calibration factor to that data point which results in the absolute spectral irradiance at $280 \mathrm{~nm}$. The system then advances to the next wavelength and this process continues, until the scan is complete. The system will also use the broadband detector as a stability monitor for the light source and will correct the spectral data based on any broadband variation throughout the scan.

The software will save the high resolution spectral data to a text file, which then can be used to classify a simulator for spectral match according ASTM E-927. ${ }^{[1]}$

Typically for a multi-pulse simulator, such as those made by Spire, a full scan takes $2-5$ minutes depending on the wavelength range of interest. However, flash simulators that require cooling and/or charging time between flashes, such as Spire's long pulse simulators, can take as much as 45 minutes or more, depending on the wavelength range and delay between flashes.

The PASS has been calibrated using a NIST FEL lamp standard at the NREL Optical Metrology Laboratory. This calibration process produces a data file that represents the instruments absolute spectral response at each wavelength. 
The calibration process also includes calibrating the wavelength drive of the system, so that it is within approximately $1 \mathrm{~nm}$ of known emission line outputs from mercury $(\mathrm{Hg})$ or xenon $(\mathrm{Xe})$ sources.

\subsection{Unique features}

What makes the PASS unique is its ability to measure the absolute spectral irradiance of a pulsed light source at any region within the pulse profile. Most commercial systems, which are actually capable of measuring a pulse light source, do so by either averaging or integrating all the data under one or more pulses. Also they may not have a way of triggering the systems reliably; not having a trigger can sometimes make it harder to capture the pulses from a simulator that does not rapidly flash multiple times during the systems acquisition period. Most of these commercial systems are only able to measure relative spectrum, whereas the PASS will give you absolute readings in units $\mathrm{W} / \mathrm{m}^{2} / \mathrm{nm}$.

Since the PASS is a grating-based system, it requires several hundred flashes to complete a spectral scan. Another unique ability of the PASS is that it can correct for any minor broad band variation of the light source that occurs during the scan, whether it is a flash or continuous simulator. NREL has yet to find any commercial grating-based monochromator systems that have this feature included.

\subsection{PASS flexibility and capabilities}

The PASS software was designed to allow the most flexibility with both automated and manual control of the instrument. All the monochromator components are stored in a configuration file in order to allow different systems to be built with different capabilities. This file includes information such as detector, grating, and filter quantities, including the wavelength at which these components should be automatically put into effect. Two PASS units have been made by NREL; one for NREL and one for Spire Solar, each with their own capabilities in terms of wavelength range. The software also includes a "Wizard" feature to quickly initiate scans for common measurement tasks.

The software has many on-screen tools to view and analyze the data while data acquisition is taking place, to assure that measurements are being done with the proper simulator and/or PASS configurations. This is especially important when doing measurements on a slow-firing pulse solar simulator, such as Spire's Long Pulse Simulators, which can take up to 45 minutes to measure. During a measurement, the user can view the current spectrum as it's collected and compare that spectrum with any previously measured data. After the scan is complete the user can view the ASTM E-927 classification of the solar simulator. Spectral data is automatically saved to disk for later analysis.

Prior to measuring a pulsed solar simulator, the user must determine where data should be taken on the pulse profiletypically on the peak of bell shaped pulses and across the flat portion of flat-top pulses. Once this is determined, the user can save this configuration for future measurements made on that simulator (or any other simulator with the same pulse characteristics). If necessary, the user can repeat this process for other simulators that have different pulse profiles.

Now the user can quickly make pulse simulator spectral measurements using a list of pre-determined positions. The user can also view the pulse data during spectrum acquisition and has the option of saving the pulse data for later analysis, such as computing the spectrum at different times within the pulse profile.

\section{PASS HARDWARE}

The PASS is composed of many off-the-shelf components, which are mentioned later in this document; however, this does not imply endorsement by the United States Department of Energy or NREL. Due to the complexity of measuring the spectrum of pulse light sources, strict requirements were set for the selection of hardware that comprises the PASS. Complete control of the monochromator components and access to the raw signals from the detectors behind the monochromator was essential and, since the PASS was to be used to measure light pulses as short as 250 microseconds, the detectors needed a fast response time. Such fast detectors could include silicon, germanium, indium gallium arsenide (InGaAs), or a photomultiplier tube (PMT). Fig. 1 shows the schematic diagram for the dual detector system used at NREL. 


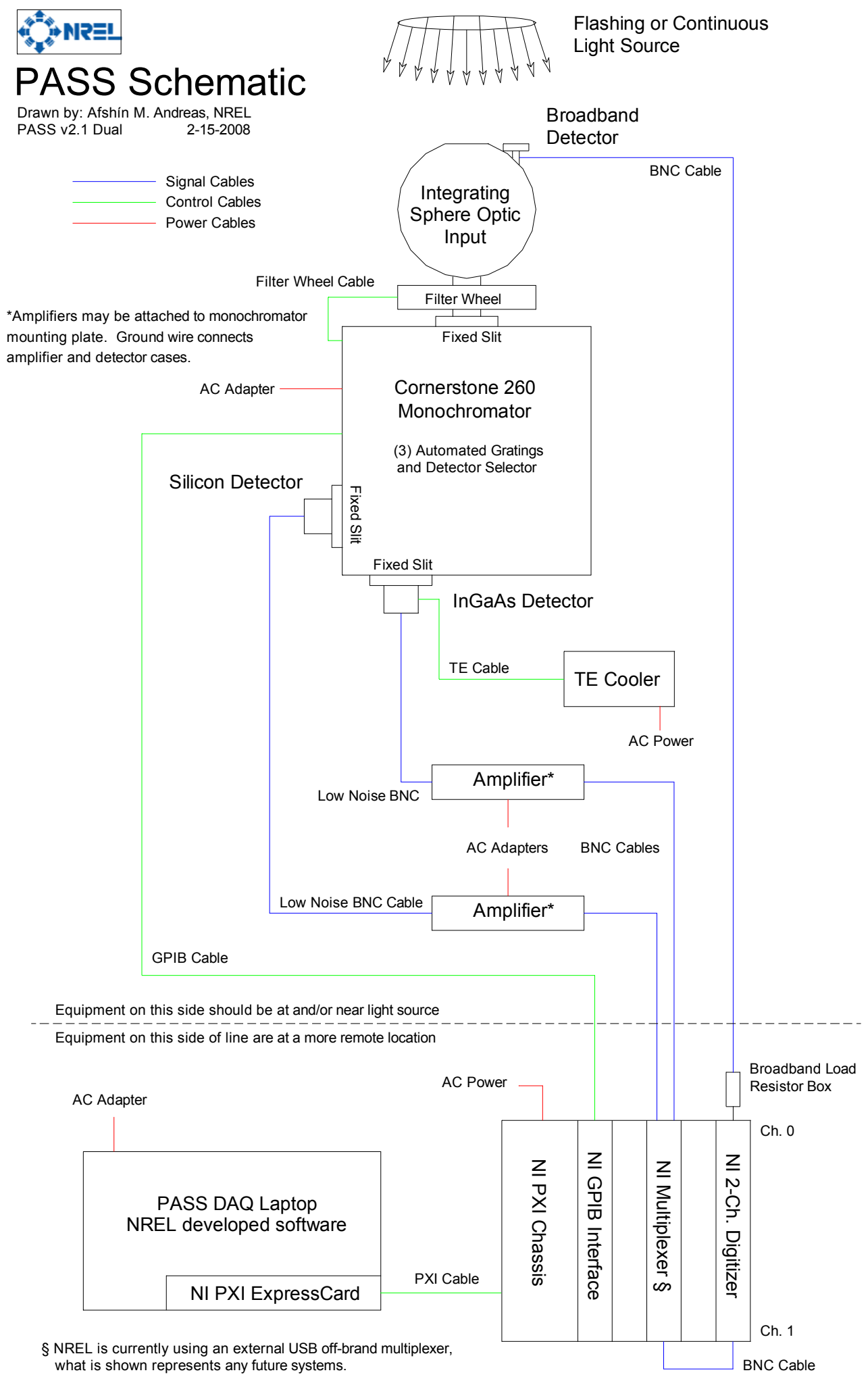

Fig. 1. Schematic for the dual detector PASS which has a wavelength range of 280 to $1720 \mathrm{~nm}$ at $5 \mathrm{~nm}$ intervals. 


\subsection{Monochromator}

For the monochromator, NREL selected the Oriel Cornerstone 260 monochromator from Newport. This monochromator was chosen because it allows control of the grating, filter wheel, detector selector, and shutter through simple commands using the GPIB or RS-232 interface. It allows up to two detectors and up to three gratings on the turret, that allow a wide range of spectral measurements from 250 up to $2800 \mathrm{~nm}$. Newport also has a wide variety of available components for the Oriel monochromators.

\subsection{Detectors}

The Cornerstone 260 monochromator supports up to two detectors. NREL is using the Oriel UV-enhanced silicon detector for wavelengths between 280 and $1100 \mathrm{~nm}$, for measurements beyond $1100 \mathrm{~nm}$ a second Oriel InGaAs detector is used. Silicon has a temperature dependence above $1000 \mathrm{~nm}$, therefore if that wavelength region is required, then a Termo Electrically Cooled (TEC) detector must be used. Since the TEC is also required for the InGaAs detector, on NREL's dual detector system, it is configured to cut-on at 1000nm, therefore the TEC is not necessary for the silicon.

\subsection{Detector amplifiers}

Since the detectors are behind a monochromator that has a spectral bandwidth of $5 \mathrm{~nm}$ or smaller, the output currents generated by the detectors are very small, in the order of nanoamps. Therefore a very high gain amplifier will be needed. NREL has tried several off-the-shelf transimpedance amplifiers and found that many did not have the bandwidth requirements necessary for measuring short duration pulses of $1 \mathrm{~ms}$ or less at the high gains of $10^{7}$ or $10^{8}$ volts/amp needed. Many of these amplifiers will distort the width and heights of the pulse, which can lead to erroneous measurements. The amplifier that was chosen for the PASS was the variable gain Femto DLPCA-200, which has the bandwidth requirements to measure such short duration pulses. It also has the advantage of being variable gain, for measurements on NREL's High Intensity Pulse Solar Simulator (HIPSS). Although most measurements are typically performed at 1 sun, which would only require a fixed gain, the HIPSS, depending on the voltage setting, can range from several suns to several hundred suns, which would require a variable gain amplifier on the PASS.

\subsection{Data acquisition and software}

The data acquisition and software parts of the PASS are all from National Instruments line of products, due to NREL's familiarity with their vast assortment of product offerings. Criteria for the PASS data acquisition include: 1) $1 \mathrm{MHz}$ sample rate, 2) 16-bit vertical resolution or more, and 3) the capability of sampling at least two channels simultaneously. Based on the product selection, NREL is using the NI PXI-5922. The PXI-5922 is mounted inside a small PXI chassis which allows for other components to be installed, such as a GPIB adapter and a signal multiplexer. The PXI chassis is then attached to a notebook computer by an ExpressCard (or a PCMCIA/PC-card in older models). The PXI chassis then acts as an extension to the PCI or PCI-express bus of the computer and the chassis itself is transparent to the operating system.

The software was developed exclusively in National Instruments LabWindows/CVI, which allows for sophisticated graphical interfaces with robust control of instrumentation, all of which is programmed through $\mathrm{C}$ code.

\section{PASS CALIBRATION AND PERFORMANCE TESTING}

NREL performs regular in-house calibrations of spectroradiometers with traceability to the National Institute of Science and Technology (NIST). The PASS is calibrated on a 6-month or an as-needed basis in NREL's optical metrology laboratory, according to ASTM E-138-96. We purchase Spectral Irradiance Standard Lamps directly from NIST. These lamps come with a data sheet that lists the spectral irradiance of the lamp at various wavelengths in the wavelength range of 250 to $2400 \mathrm{~nm} .{ }^{[2]}$

The PASS calibration is performed using the continuous measurement mode, where the system averages the signal data for an entire second at each wavelength, and then computes a calibration factor based on the NIST provided irradiance at that wavelength divided by the measured signal in amps from the detector. 
After calibration, the system is verified by measuring a 150-watt Oriel Simulator and a Spectrolab Large Area Continuous Solar Simulator (LACSS) and comparing the results with measurements made by an Optronic Laboratories OL750, which is also calibrated at NREL. The measured spectrum of the PASS agrees to within $2 \%$ of the OL750. [Fig. 2]

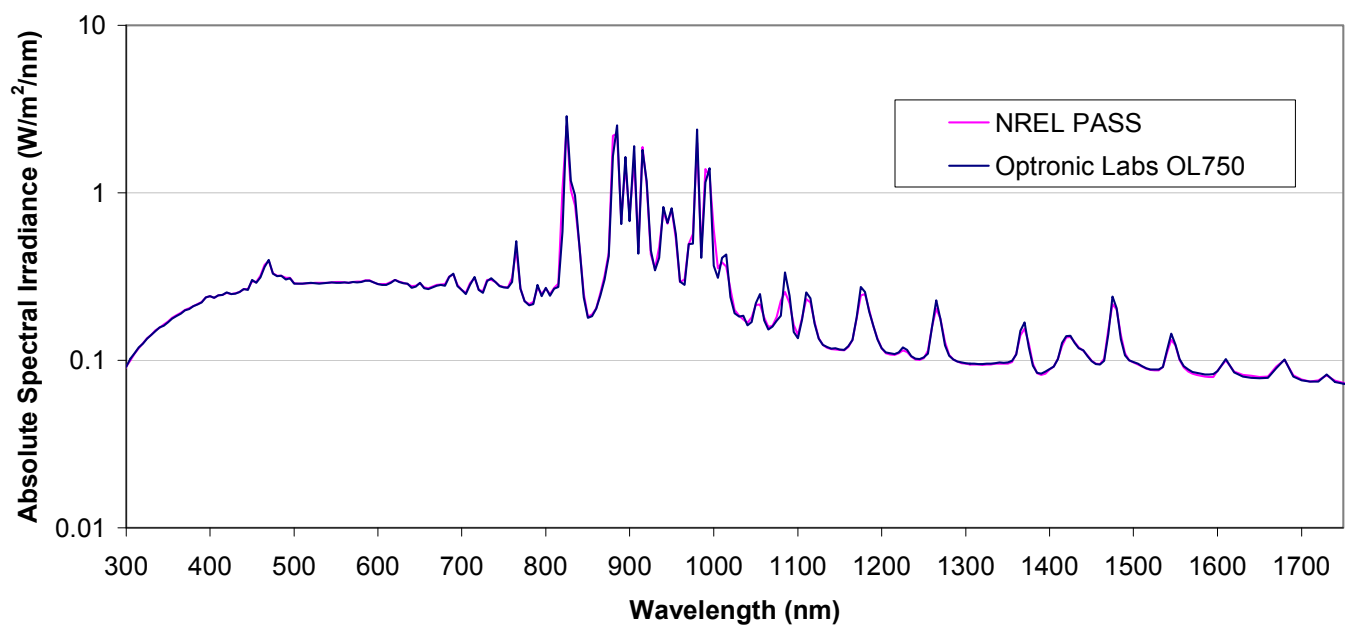

Fig. 2. PASS measured spectrum of continuous Oriel Solar Simulator Model 66902 (unfiltered) compared to OL750.

The repeatability of the PASS measurements are checked with continuous light sources, such as the NIST FEL lamps, Oriel, and Spectrolab simulators. The repeatability of the PASS (and light sources) was $+/-0.2 \%$ for the FEL lamp and the simulators were approximately $+/-1 \%$. [Fig. 3]

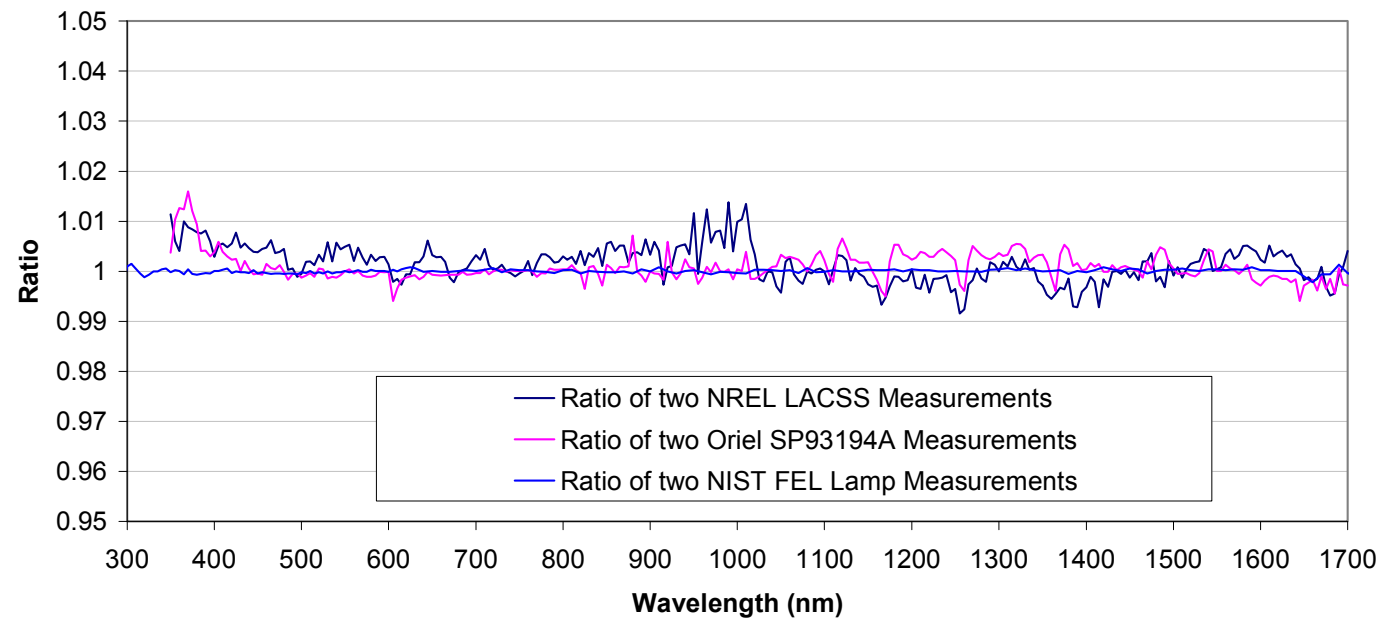

Fig. 3. PASS repeatability testing with continuous light sources. NIST FEL lamp shows $+/-0.2 \%$ repeatability.

Once the calibration and repeatability was verified with continuous sources, it was then verified using light sources for which it was primarily designed for-pulsed light. We measured the NREL Spire SP240A pulsed simulator. This simulator has known problems with the flash-to-flash repeatability; therefore as the spectrum was being measured (one flash per wavelength) the broadband intensity of the light was fluctuating by $+/-5 \%$ resulting in the ratio of the two spectral scans differing by as much as $+/-5 \%$ or more. However, since the PASS has the ability to automatically correct the spectral data due to broad band intensity instability, the ratio of broad band corrected spectra agreed to within $+/-1 \%$. [Fig. 4] 


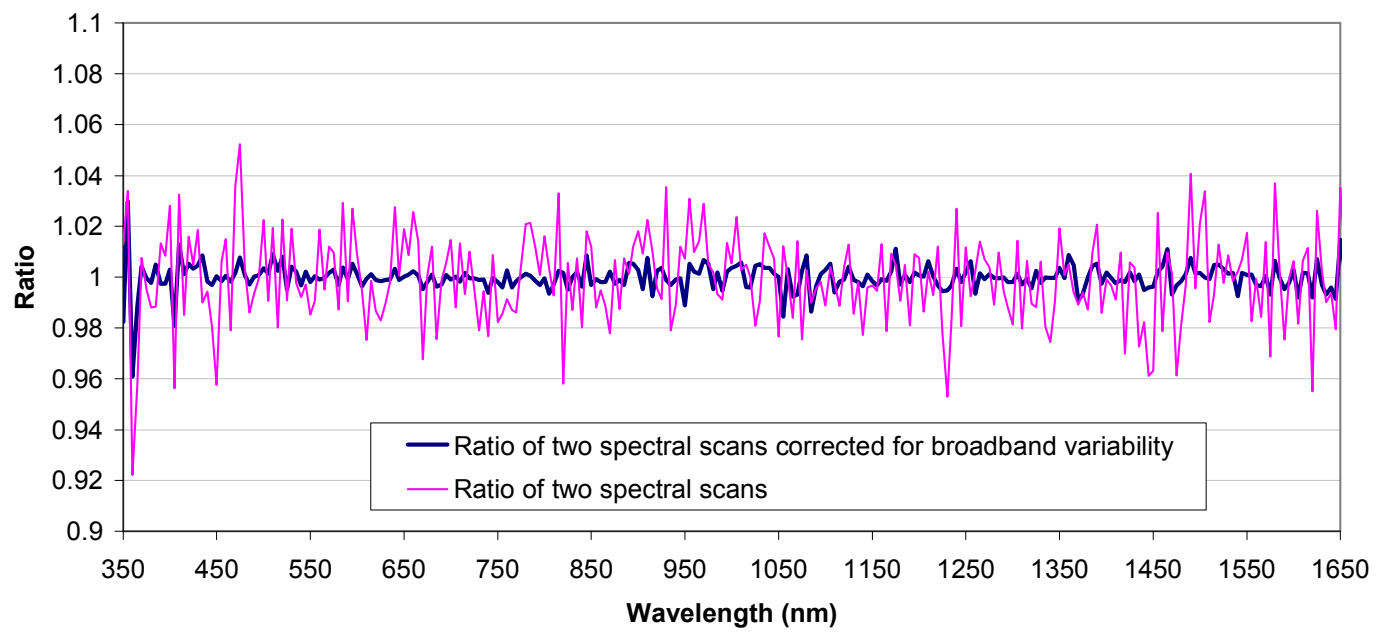

Fig. 4. PASS repeatability testing with SP240A pulse solar simulator. Thicker line shows broad band corrected spectral ratios.

To verify the pulse measurement capability the spectral measurements are compared to an Optronic Laborories OL750 running in pulse measurement mode (PMM). The OL750 PMM is not capable of taking data on the peak of the pulse, it simply integrates the entire energy in one or more pulses over a specified time. Therefore the PASS is configured so that it acquires data during an entire pulse for this comparison. The measured spectrum of the PASS agreed to within $2 \%-5$ $\%$ of OL750 [Fig. 5].

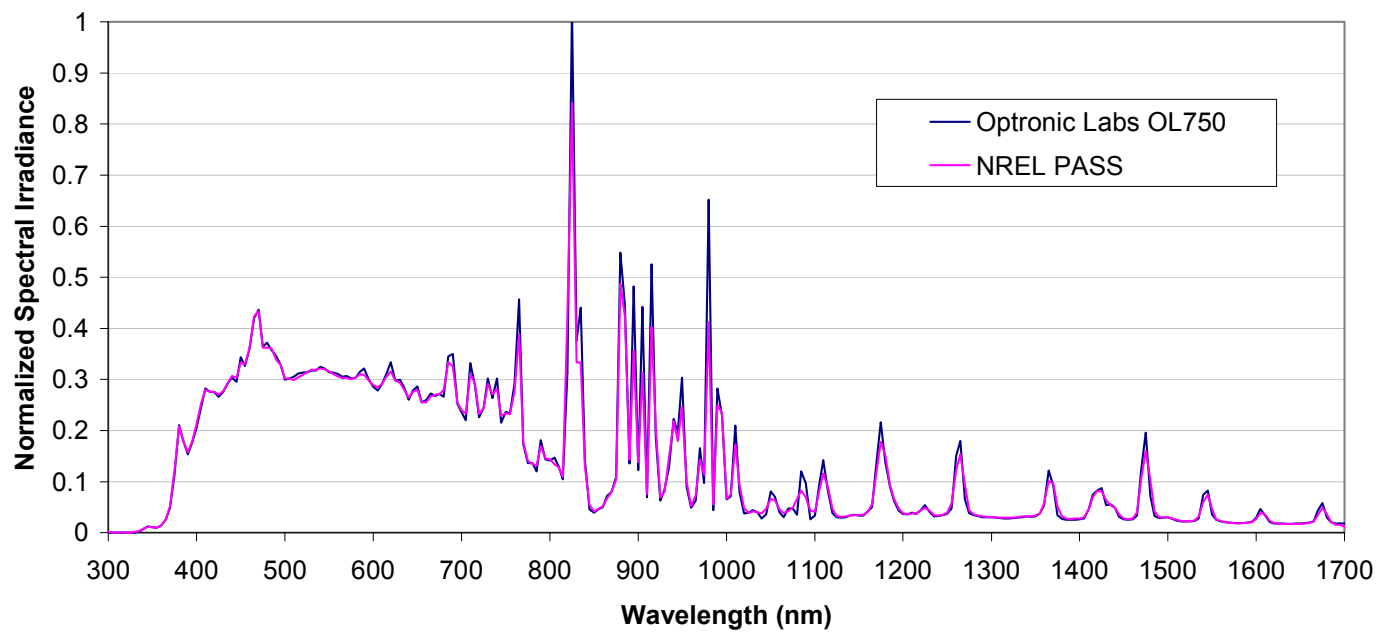

Fig. 5. PASS measured spectrum of SP240A compared to OL750 PMM.

Now that that pulse measurement capability of the PASS has been verified, the software can be configured to acquire data only on the peak of the pulse, where the measurements of a typical PV device is normally tested on a pulsed solar simulator.

This shows that measuring the entire pulse, rather than the preferred peak, results in a spectrum that is $2 \%-4 \%$ low for wavelengths less than $800 \mathrm{~nm}$ for this type of pulsed simulator. [Fig. 6] In most cases this can be considered negligible if the only intent is to produce a classification for the simulator, because the ASTM E-927 allows up to $+/-25 \%$ deviation from the reference spectrum to still be considered Class A for spectral match. ${ }^{[1]}$ 


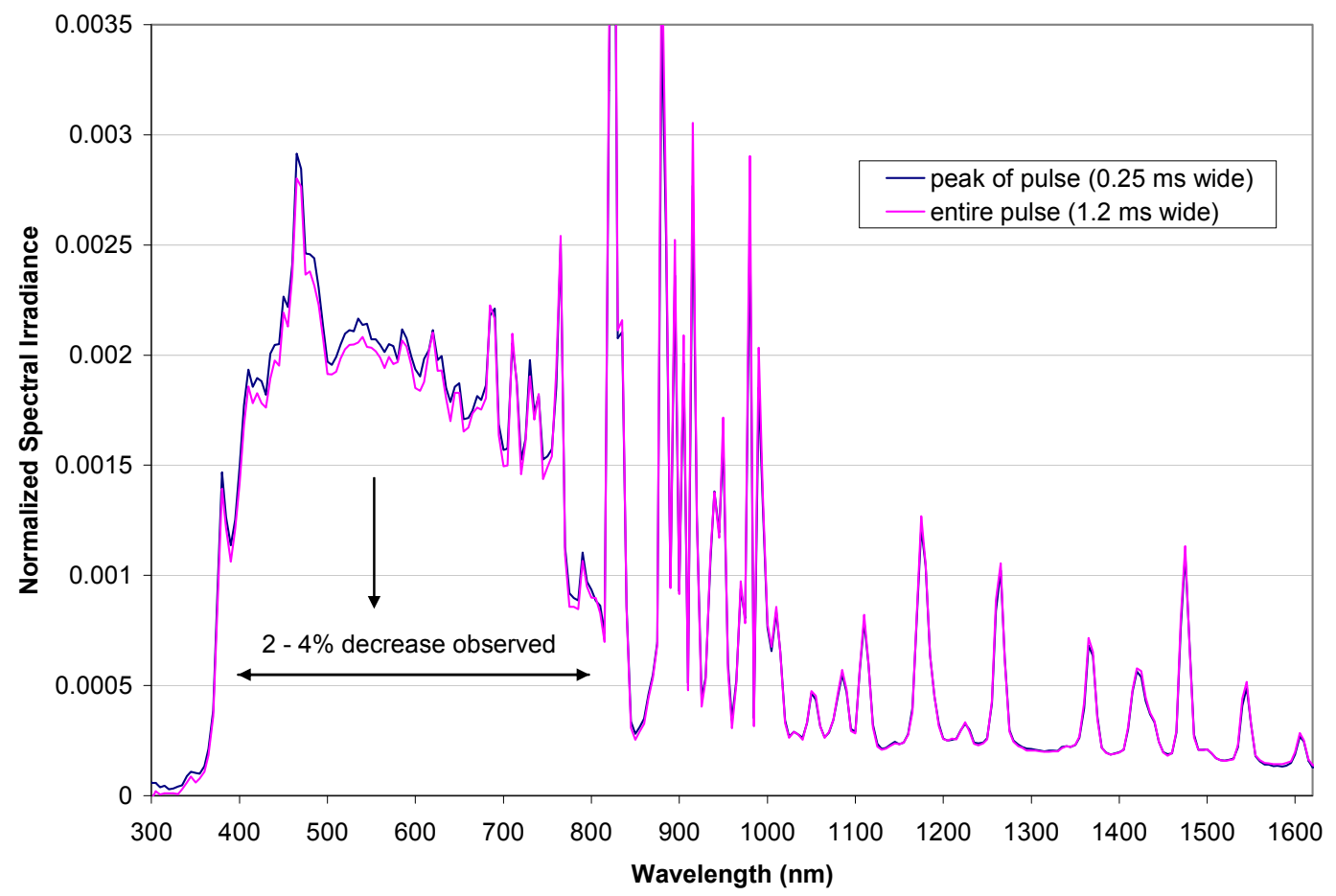

Fig. 6. Effect on spectrum when measuring using entire pulse results in a $2 \%-4 \%$ lower intensity for wavelengths below $800 \mathrm{~nm}$. The two spectrum required area normalization, because data is being averaged on rising and trailing edge of the pulse which reduces the overall measured intensity. For this test the spectrum at each wavelength was captured only once, then a spectrum was computed using the entire pulse (1.2 ms wide) and then at the peak $(0.25 \mathrm{~ms})$. This would remove any affects due to repeatability of the solar simulator or the PASS.

This test was also performed on Spire SP3500 Multi Pulse and a SP4600 Single Long Pulse (SLP) and the same results were observed.

\section{SPECTRAL MEASUREMENTS PERFORMED BY NREL USING THE PASS}

NREL has used the PASS to measure the spectrum of at least 13 different pulse solar simulator models from manufacturers including: Spire Solar, Spectrolab, Berger Lichttechnik, and Spheral Solar. The pulses from these simulators were as small as $0.25 \mathrm{~ms}$ bell shape curves to as large as a $100 \mathrm{~ms}$ flat top pulse, two example pulse shapes from NREL simulators are shown in Fig. 7. 


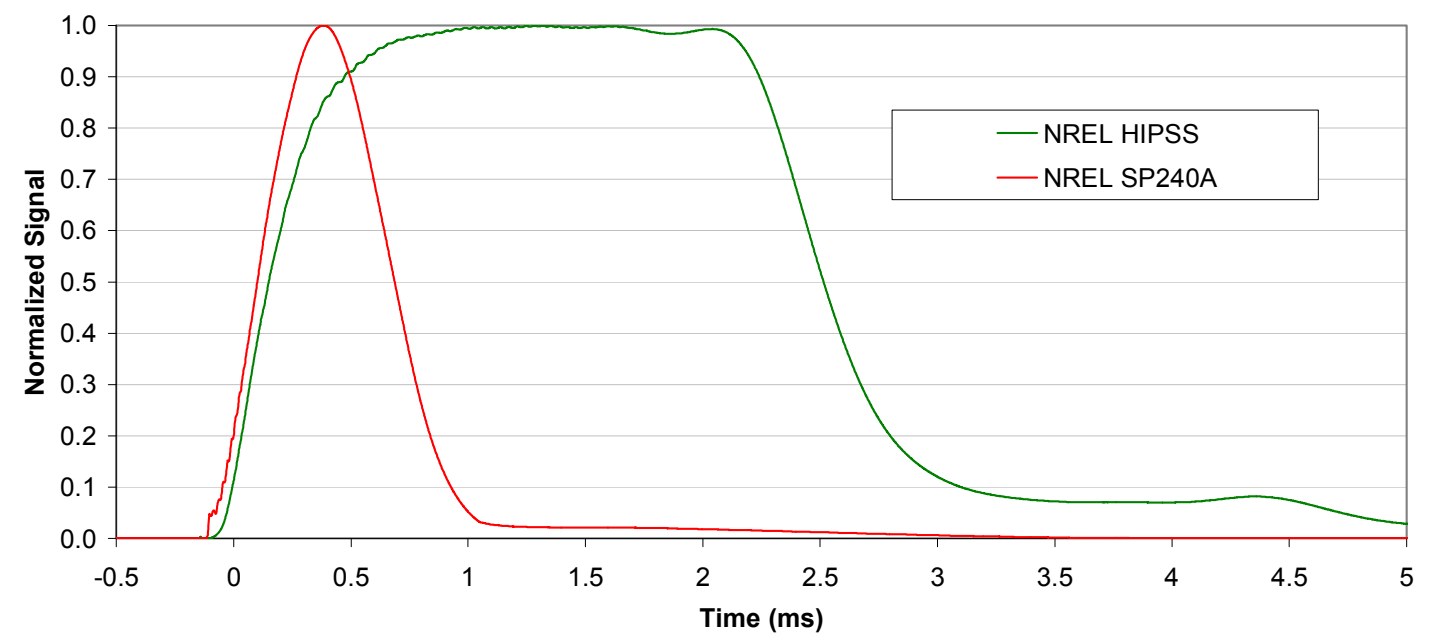

Fig. 7. Example pulse profiles from NREL solar simulators. Bell shape curve is from SP240A and flat top is from HIPSS.

The PASS has been used to measure and classify solar simulators for spectral match under the ASTM E-927-04. This includes both in-house simulators and at least eight outside companies. The Spire SP240A at NREL and the Spire SP660 at the Florida Solar Energy Center (FSEC) are measured annually using the PASS. The following is an example ASTM E-927 chart showing that the SP240A is Class A for spectral match [Fig. 8]. The spectral data is compared to the reference global spectrum in ASTM G-173. ${ }^{[1][3]}$

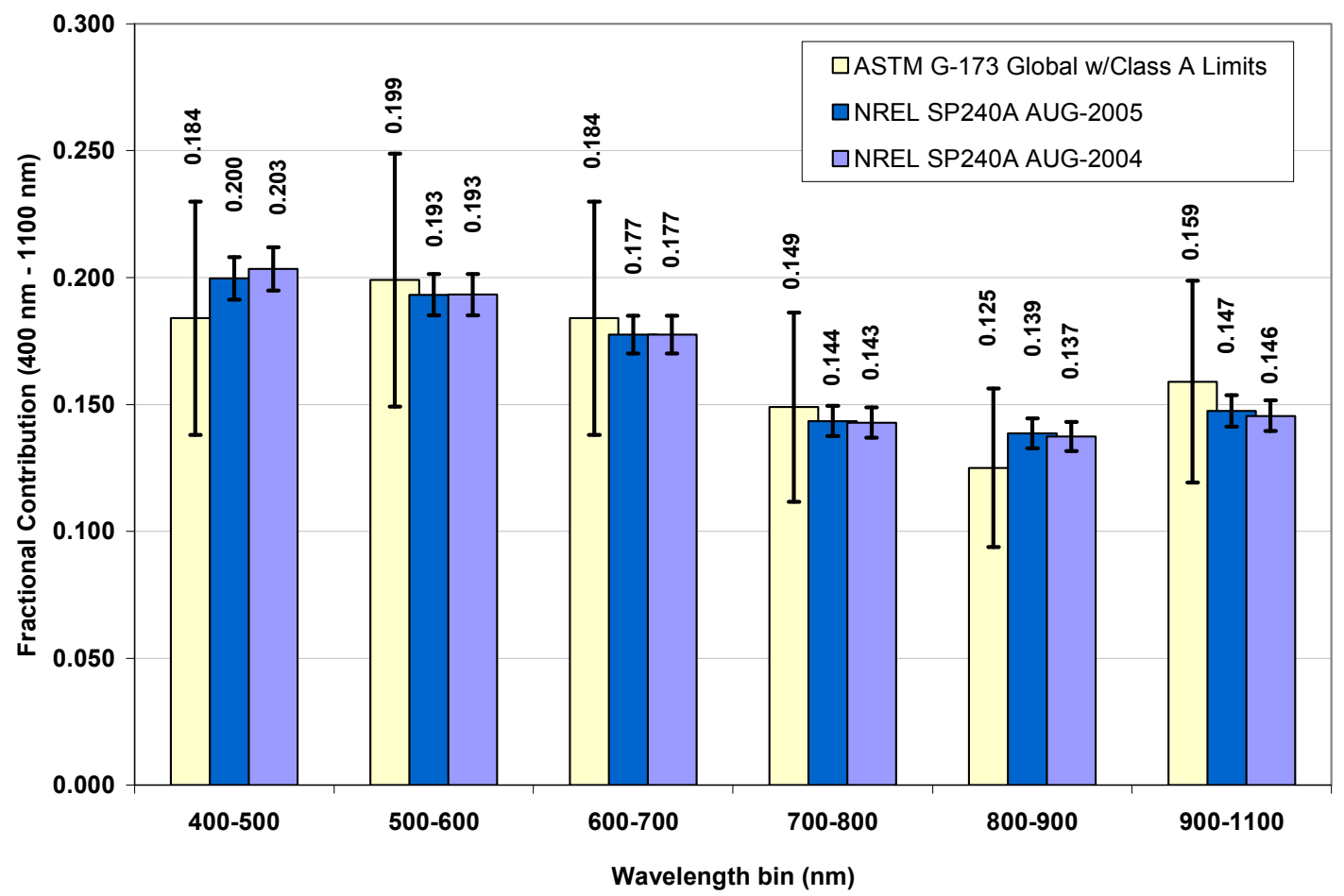

Fig. 8. ASTM E-927-04 spectral classification of NREL SP240A pulse solar simulator from August 2004 and 2005. Error bars on G-173 reference spectrum are permitted deviation under ASTM E-927 for Class A. Error bars on measured data is the measurement uncertainty of the PASS. 
NREL has performed numerous spectral measurements of the NREL High Intensity Pulsed Solar Simulator (HIPSS) using the PASS. One study was performed by running the simulator at seven different voltages, which corresponded to approx. 20 to 300 sun intensity on the test bed. These tests showed that the spectrum at low voltage were dominated by xenon emission spikes, however at higher voltages these spikes were indistinguishable from the rest of the spectrum.

[Fig. 9]

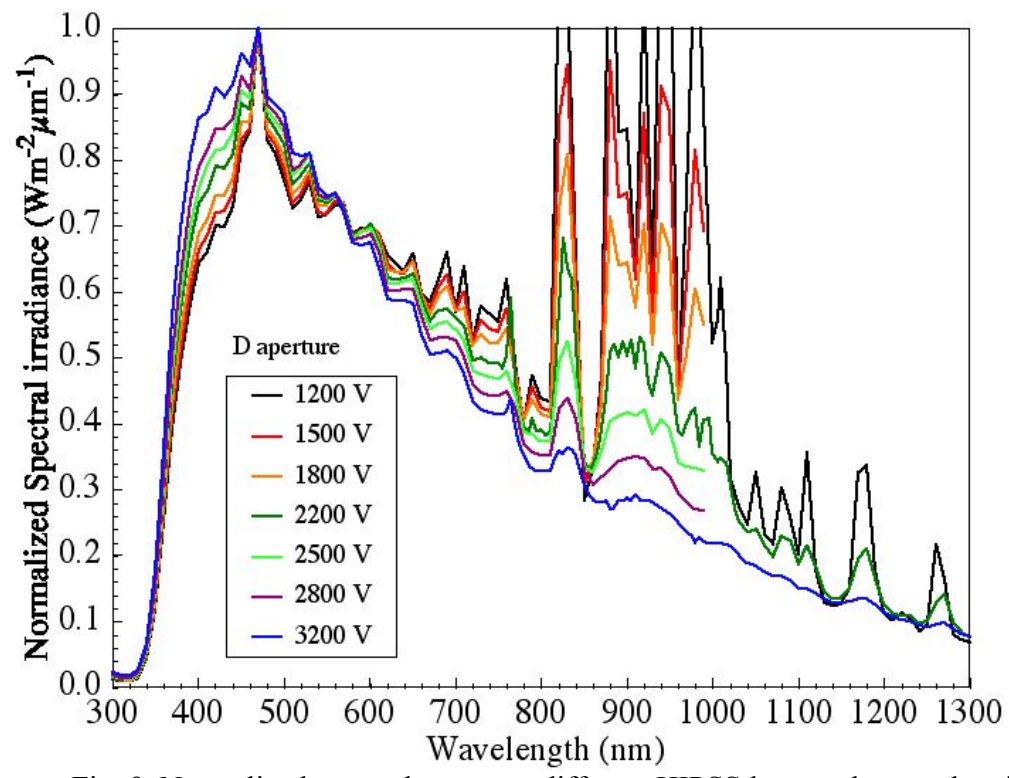

Fig. 9. Normalized spectral curves at different HIPSS lamp voltages, showing Xe emission spikes diminish at high voltage.

These spectral shifts were also demonstrated using the ratio of short circuit current densities from single junction cells in a typical triple junction cell. As the voltage increases, the ratio between the junction types shifted, signaling a change in the spectral content of the flash, due to differences in the spectral response of each cell. ${ }^{[4]}$

Studies were also conducted to determine whether or not there was a spectral shift over the life of an individual pulse. This showed that energy toward the end of the pulse contained more infrared than ultraviolet. [Fig. 10]

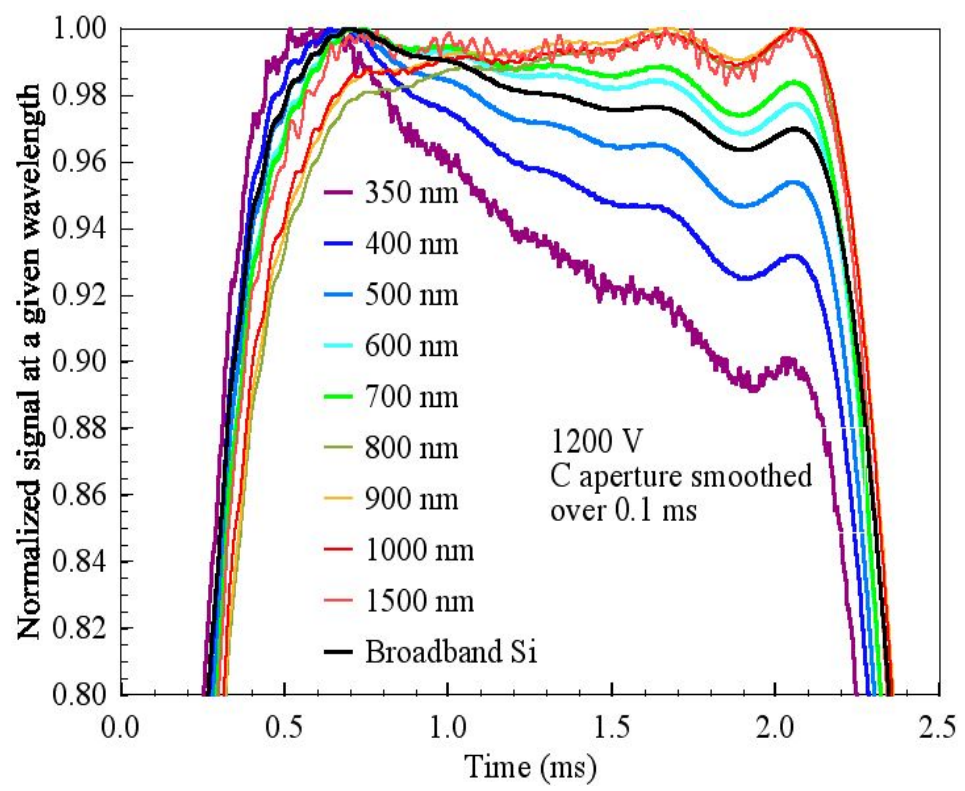

Fig. 10. HIPSS pulse profiles at different wavelengths, showing that UV is reduced toward the end of pulse life. 


\section{FUTURE WORK}

The PASS has gone through improvements and upgrades since it was first developed and there is still room for improvement. The current InGaAs detector is limited to $1700 \mathrm{~nm}$ and there is desire at NREL for spectral data beyond that. Since the detector must have a very fast response, an Extended IR InGaAs detector may be purchased soon to allow measurements up to 2200 to $2400 \mathrm{~nm}$.

One disadvantage of the PASS is performing routine measurements on slow-firing pulse simulators. Depending on the simulator flash rate, the measurement could take up to several hours. An example of this is the NREL HIPSS, which requires 1 minute cool time between each flash. A full, high resolution measurement from $300 \mathrm{~nm}$ to $1700 \mathrm{~nm}$ at $5 \mathrm{~nm}$ intervals takes up to 280 minutes to perform. Most pulse simulators, like the multi-pulse Spire solar simulator, takes just under 5 minutes to measure. To improve the speed of the PASS, a diode array would be necessary so that the spectrum can be measured in one flash, rather than one flash per wavelength. In order to reach the wavelength range desired, both a silicon and InGaAs array would be required. Due to possible accuracy issues, the diode arrays were not pursued in the original development of the PASS.

There also has been commercial interest in the PASS, which could yield further improvements and expose the system to a broader user base.

\section{SUMMARY}

The PASS has proved to be an invaluable resource to both NREL and industry for evaluating the spectral content of pulse solar simulators. The data from the PASS has many uses and the system can be tailored to most measurement needs. Future improvements to the system could yield a wider wavelength range, as well as the possibility of acquiring the spectrum at a more rapid rate.

\section{ACKNOWLEDGMENTS}

The authors would like to thank Ted Cannon, who designed the first PASS unit for which this new and improved system is based on; Keith Emery, who provided many suggestions on how to improve the operation and accuracy of the system; and the NREL Photovoltaic Performance and Characterization Team, who allowed us extensive use of their pulsed solar simulators during the development and testing of the PASS. This work was supported by the U.S. Department of Energy under Contract No. DE-AC36-99GO10337 with the National Renewable Energy Laboratory.

\section{REFERENCES}

[1] ASTM Standard E-927-04, "Standard Specification for Solar Simulation for Photovoltaic Testing," ASTM International, West Conshohocken, PA, www.astm.org.

[2] ASTM Standard E-138-96, "Standard Test Method for Calibration of a Spectroradiometer Using a Standard Source of Irradiance," ASTM International, West Conshohocken, PA, www.astm.org.

[3] ASTM Standard G-173-03, "Standard Tables for Reference Solar Spectral Irradiances: Direct Normal and Hemispherical on $37^{\circ}$ Tilted Surface," ASTM International, West Conshohocken, PA, www.astm.org.

[4] J. Kiehl, K. Emery, and A. Andreas, "Testing Concentrator Cells: Spectral Considerations of a Flash Lamp System," Proc. 19th European PVSEC, 2463-2465 (2004). 


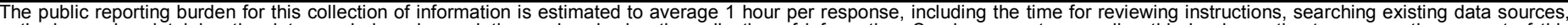

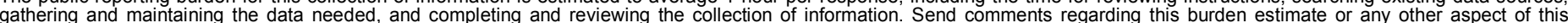

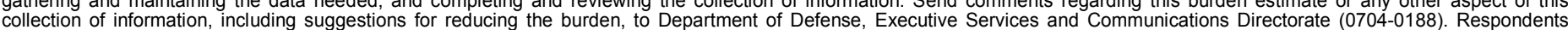

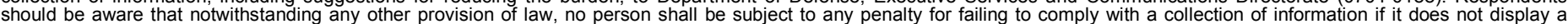

should be aware that notwithstanding

PLEASE DO NOT RETURN YOUR FORM TO THE ABOVE ORGANIZATION.

\begin{tabular}{l|l|l|l} 
1. REPORT DATE $(D D-M M-Y Y Y Y)$ & 2. & REPORT TYPE & 3. DATES COVERED (FrOm - TO)
\end{tabular}

July 2008

Conference Paper

4. TITLE AND SUBTITLE

Pulse Analysis Spectroradiometer System for Measuring the

Spectral Distribution of Flash Solar Simulators: Preprint

5a. CONTRACT NUMBER

DE-AC36-99-GO10337

5b. GRANT NUMBER

5c. PROGRAM ELEMENT NUMBER

6. AUTHOR(S)

A.M. Andreas and D.R. Myers

5d. PROJECT NUMBER

NREL/CP-581-43652

5e. TASK NUMBER

PVB77301

5f. WORK UNIT NUMBER
7. PERFORMING ORGANIZATION NAME(S) AND ADDRESS(ES)

National Renewable Energy Laboratory

1617 Cole Blvd.

Golden, CO 80401-3393
8. PERFORMING ORGANIZATION REPORT NUMBER

NREL/CP-581-43652

9. SPONSORING/MONITORING AGENCY NAME(S) AND ADDRESS(ES)

10. SPONSOR/MONITOR'S ACRONYM(S) NREL

11. SPONSORING/MONITORING AGENCY REPORT NUMBER

12. DISTRIBUTION AVAILABILITY STATEMENT

National Technical Information Service

U.S. Department of Commerce

5285 Port Royal Road

Springfield, VA 22161

13. SUPPLEMENTARY NOTES

14. ABSTRACT (Maximum 200 Words)

Flashing artificial light sources are used extensively in photovoltaic module performance testing and plant production lines. There are several means of attempting to measure the spectral distribution of a flash of light; however, many of these approaches generally capture the entire pulse energy. We report here on the design and performance of a system to capture the waveform of flash at individual wavelengths of light. Any period within the flash duration can be selected, over which to integrate the flux intensity at each wavelength. The resulting spectral distribution is compared with the reference spectrum, resulting in a solar simulator classification.

15. SUBJECT TERMS

spectral distribution; solar simulator classification; flash solar simulator; pulse measurement system; waveform capture; spectroradiometer; monochromator; artificial light

\begin{tabular}{l|l|l|l|l|}
\hline $\begin{array}{l}\text { 16. SECURITY CLASSIFICATION OF: } \\
\begin{array}{l}\text { a. REPORT } \\
\text { Unclassified }\end{array}\end{array}$ & $\begin{array}{c}\text { b. ABSTRACT } \\
\text { Unclassified }\end{array}$ & $\begin{array}{c}\text { c. THIS PAGE } \\
\text { Unclassified } \\
\text { OF ABSTRACT }\end{array}$ & $\begin{array}{c}\text { UL } \\
\text { OF PAGES }\end{array}$ \\
\hline
\end{tabular}

19a. NAME OF RESPONSIBLE PERSON

19b. TELEPHONE NUMBER (Include area code) 